\title{
Research on the Application of Traditional Decorative Elements in Contemporary Architectural Design
}

\author{
Jun Yan, Xiaoxian Shan
}

(Jingdezhen Ceramic Institute, 333000, Jingdezhen, Jiangxi, China)

Key words: modern architectural design; traditional decorative elements; applied research.

\begin{abstract}
With the rapid development of building decoration technology, more and more new materials are used in architectural design, in order to meet people's function use, to meet people's spiritual needs in the process, the decoration technology plays a key role. But at the same time, people began to focus on the traditional decorative elements to dig treasures, in order to achieve the traditional and modern organic combination, to create a unique and personalized design atmosphere, get rid of the modern design of the pale and mechanical.
\end{abstract}

\section{Introduction}

The level of the development of modern architectural design is relatively high, especially the use of some new, environmentally friendly design materials, but also enhance the overall level of architectural design. But at the same time, the modern architectural design style also tends to assimilate, it lost the personality and style. The overall uniform design styles has increased the people's aesthetic fatigue and visual fatigue in the invisible. Based on this, in the contemporary architectural design, actively seeking the integration of modern design and traditional decorative elements, not only to highlight the design of the individual, but also to enrich the design language, enrich modern design form.

\section{Traditional Decorative Elements Classification}

Traditional decorative elements have a typical era of branding, it is the crystallization of people's wisdom, but also is the perfect fusion of people's practice and natural material. Traditional decorative elements in the use of architectural design, mainly are based on the architectural space of the landscaping and architectural decoration in order to achieve the purpose of perfect fusion, giving a good visual enjoyment, so that people can feel the beauty through intuitive vision,form a good mood to release.

2.1 Traditional Decorative Elements Full of Moral Elements. Traditional decorative elements of the subject matter are very rich and diversified, and most of these themes come from people's practice of life, especially with a sense of picture, and almost every picture has a good moral, a symbol of good expectations and longing. Such as industrious farmers, flying birds, jumping carp and so on. No matter what subject matter, they all contain a rich moral, which is the most typical characteristics of traditional decorative elements. In the process of selecting the subject matter, people fully play their own ingenuity, as well as the deep connotation of traditional culture, the external visual arts and internal emotional elements were closely linking in order to form a complete picture. In the determination of the content of the traditional decorative elements, people use the "homophonic" in Chinese to interpret and express the inner beauty and wishes of people, such as "deer" to express the meaning of the wealth and health. In the mix and composition of the subject matter, the choice of content of people is more free and inclusive, as long as it is a symbol of good things, as long as it is able to express the good meaning, it can be applied to the traditional decorative elements.

\subsection{Performance of Traditional Decorative Elements in Painted Sculpture}

In the process of the use of traditional decorative elements, people tend to strive for perfection and art, mainly by means of painting, sculpture and so on to present a good meaning of the decorative 
theme. Therefore, the expression form of the traditional decorative elements including painting, sculpture and so on.First, the use of painting people's cognitive and research of the color to a certain extent, through different combinations of colors, by fitting the actual painting as much as possible to express people's inner beauty and desire. Painting is the main form of traditional Chinese decorative elements, generally directly on the appearance of the building and the core components, and strive to express the meaning intuitively and accurately, such as doors and windows, window lattice, brackets and other building wood components. [1] Second, the carving is a perfect combination of wooden crafts and architectural design. Traditional architecture is mainly composed of wood, people in the process of building design, often carve directly in the wood structure. There is much the same on carving theme and traditional architectural decoration of the subject, they all expressed people's goodness and hope. With the development of the carving process, in addition to the traditional direct carving, some relief is gradually emerging. Engraving in the architectural design of the main expression, in addition to representing people's hopes and sustenance, It performed more elegant. With the development of the construction industry, stone, brick, etc. also has gradually appeared, and widely used in architectural design. Such as the entrance to the stone road, through a large round stone carving to distinguish between the entrance hall and the inner hall, and then such as hollow brick as a looming partition, to create a " the truth dawns on one in a flash " atmosphere.

\section{Application of Traditional Decorative Elements in Contemporary Architectural Design}

Although the level of modern architectural design has been improved, people can use the design concept more diversified, the use for the design and transformation of the types of materials are also expanding, but at the same time, the modern design of the pale and lack of personality, is also criticized by people. Based on this, in the contemporary architectural design, pay attention to the use of traditional decorative elements, not only able to rejuvenate the charm of traditional decorative elements and value, but also to enrich and expand the modern architectural design elements and themes to create a unique and personalized architectural design, and constantly improve the level of modern architectural design.

\subsection{Direct Reference to Traditional Decorative Elements}

In the modern architectural design, in addition to vigorously expand the direction of modern design, research and use of new design materials, people also pay attention to actively mining treasures from the traditional decorative elements and its directly use it in modern architectural design. A direct reference to traditional decorative elements is a major feature of modern architectural design. Traditional decorative elements in a lot of simple and clear patterns, in line with people's simple aesthetic needs, in line with the contemporary people to enjoy the spirit of rapid, so it is widely used for direct reference. Such as the traditional decorative elements in the pattern, texture, etc., with smooth lines, simple color, simple composition and other styles and characteristics, it was directly quoted in the design of the tables and chairs, partition design and some corridors, window lattice and other design. Traditional decorative elements of the direct reference, can effectively enrich the modern architectural design elements. In order to highlight the modern design style, people tend to be in color or lines, the simplicity of the design to rejuvenate the vitality of traditional decorative elements. Practice has proved that the direct reference to the traditional decorative elements, not only will not seem nondescript,bring some visual error, causing people's resentment, to opposite it can increase the background of the modern architectural design, expand the direction of modern architectural design.

\subsection{Abstract Elements of Traditional Decorative Elements}

In the modern architectural design, the use of traditional decorative elements, direct reference to the part often stay in the simple lines and other basic content. Most of the traditional decorative elements in the practical application, need a high degree of generalization and abstraction of the treatment, making the traditional decorative elements glow new vitality, to meet the modern 
people's simple and intuitive aesthetic needs.[2] First, in the modern architectural design, people has simplified the traditional geometric patterns to a certain extent, to highlight its simple beauty and image sense, so that people can understand the meaning of geometric patterns intuitively. This is the traditional decorative elements to meet the needs of contemporary transformation and upgrading, but also the traditional decorative elements of the main channel of vitality. Second, in the modern architectural design, people on the traditional decorative elements of a certain refinement, generally the main refining its charm, to retain its most valuable artistic beauty and probation function, remove the complex structure, to reflect the beauty of this design and core values. Third, for the use of traditional decorative elements, people will use 3D projection and other advanced technology to change the traditional decorative elements of the geometric ratio, making it to zoom in or out to meet the actual use. Fourth, in the process of the use of traditional decorative elements, people retain the thinking of the theme based on respect for the subject, but in the structural design, make it to be modernized. For example, the traditional decorative elements in the layout of modern architectural design, in the full retention of the main idea on the basis of its three-dimensional processing and presentation.

\subsection{Decomposition and Reconstruction of Traditional Decorative Elements}

In the modern architectural design, the use of traditional decorative elements, whether it is directly used or abstract summary, they all are based on the traditional elements of the main idea of the same or similar basis. In order to make better use of the traditional decorative elements, based on the highly developed modern design technology, people also carried out the corresponding decomposition and reconstruction. First of all, the decomposition of traditional decorative elements, divided the traditional decorative elements into a number of individual parts, fully study the characteristics of the individual in the actual use, you can use the individual part, you can also use a number of individual compositions of the new content, to integrate into the modern design concept, comprehensively enhance the traditional decorative elements of modern vitality. Secondly, the reconstruction is based on the comprehensive understanding of the individual parts of the traditional decorative elements, based on the laws of science, the use of modern architectural design means to achieve scientific reconstruction. In the process of refactoring, we usually tend to be based on the direction of the adjustment, the change of the sized so on.

\section{Conclusion:}

The rapid development of contemporary architectural design technology, besides meeting people's material needs and spiritual needs, but it also existed similar design, single type and other defects. Therefore, in the modern architectural design, excavate treasures actively from the traditional decorative elements, and actively use the traditional decorative elements of the subject matter and form, in order to optimize the level of modern architectural design.

\section{References:}

[1] Wei Na, the traditional elements in the modern architectural design of the use of [J], research, 2017 (3): 253-253.

[2] Lu Yan, Zhang Shunfeng, the application of traditional elements in modern architectural decoration design [J], doors and windows, 2016 (6): 145-145. 